\title{
Katholischer Medienpreis 2006
}

Den Katholischen Medienpreis 2006 erhielten

\section{Cornelia Klaila und Tilmann Kleinjung in der Kategorie elektronische Medien sowie Mario Kaiserin der Kategorie Printmedien.}

Der Preis wurde vom Vorsitzenden der Deutschen Bischofskonferenz, Karl Kardinal Lehmann, am 9. Oktober 2006 in Bonn verliehen und ist in jeder Kategorie mit 5.000 Euro dotiert.

Cornelia Klaila (Pressesprecherin bei der Hypo-Vereinsbank, München, und freie Autorin im Bayerischen Rundfunk) und Tilmann Kleinjung (evangelischer Theologe und Redakteur beim Bayerischen Rundfunk) erhielten die Auszeichnung für ihr Radiofeature „Niemand hat mir gesagt, dass es so weh tut - Weiterleben nach dem Tsunami“, das am 26.12.2005 im Bayern2Radio ausgestrahlt wurde. Das Radiofeature lässt Menschen zu Wort kommen, die den Tsunami am 2. Weihnachtstag 2004 in Südostasien erlebt und überlebt haben. Protagonistin ist eine jüngere Frau. Ihre Tagebuchaufzeichnungen, eine Art innerer Dialog, spiegeln den existenziellen Kampf, im Strudel kaum zu benennender Trauer um den Verlust von Angehörigen eine Balance zu finden. Man versteht sehr schnell: Ein Schlussstrich wird unter eine solche Katastrophe nie gezogen werden können. Inhaltlich wie radiohandwerklich brillant inszeniert - so die Jury -, entsteht durch das Feature eine eigentümliche Dynamik. Die Autoren weichen der Fassungslosigkeit nicht aus. Tod, Verlust, tiefste Bodenlosigkeit - dennoch finden sich zwischen den Zeilen Aspekte der Hoffnung und Zuversicht, Perspektiven für ein Weiterleben. Übergänge werden spürbar.

Mario Kaiser (Autor beim „Spiegel“) erhielt den Preis für seine Reportage „Die Kunst der Sozialklempner" (erschienen in: „Der Spiegel“, Nr. 35/2005, 29.8.2005). Darin schildert er am Beispiel eines Landarztes in Mecklenburg-Vorpommern, einer Sozialarbeiterin in Leipzig und eines Streetworkers in Hamburg, wie Menschen versuchen, den Sozialstaat an seinen Bruchstellen zusammenzuhalten. Dem Autor gelingt es, die Diskussion über den Sozialstaat aus der Sphäre des Abstrakten zu lösen und sie auf den Boden von leicht nachvollziehbaren Alltagserfahrungen zu stellen. Er liefert journalistisch dichte Beschreibungen von Personen, die sich ungeachtet eigener physischer und psychischer Belastungen unablässig darum bemühen, dass Menschen, die ganz unten sind, nicht vollends aus der Gesellschaft rutschen. Durch ihre Arbeit, so unter- 
schiedlich sie ist, fließt ein Strom der Liebe. So setzen sie Zeichen der Hoffnung, verbreiten Optimismus in einer Zeit, in der viele vor den Problemen des Alltags kapitulieren möchten. Die Jury würdigt damit eine journalistische Leistung, die nicht nur auf die Schwächen und enger werdenden finanziellen Spielräume des Sozialstaates verweist, sondern Menschen zur sozialen Eigen- und Mitverantwortung ermuntert.

Beide ausgezeichneten Beiträge, so die Jury, fördern die Orientierung an christlichen Werten. 